University of Nebraska - Lincoln

DigitalCommons@University of Nebraska - Lincoln

Faculty Publications - Textiles, Merchandising and Fashion Design

Textiles, Merchandising and Fashion Design,

Department of

2010

Developing Water Stable Gliadin Films Without Using Crosslinking Agents

Narendra Reddy

University of Nebraska - Lincoln, nreddy3@unl.edu

Yiqi Yang

University of Nebraska-Lincoln, yyang2@unl.edu

Follow this and additional works at: https://digitalcommons.unl.edu/textiles_facpub

Part of the Art and Design Commons

Reddy, Narendra and Yang, Yiqi, "Developing Water Stable Gliadin Films Without Using Crosslinking Agents" (2010). Faculty Publications - Textiles, Merchandising and Fashion Design. 23.

https://digitalcommons.unl.edu/textiles_facpub/23

This Article is brought to you for free and open access by the Textiles, Merchandising and Fashion Design, Department of at DigitalCommons@University of Nebraska - Lincoln. It has been accepted for inclusion in Faculty Publications - Textiles, Merchandising and Fashion Design by an authorized administrator of DigitalCommons@University of Nebraska - Lincoln. 
Published in Journal of Polymers and the Environment 18 (2010), pp. 277-283; doi: 10.1007/s10924-010-0193-0

Copyright (C) 2010 Springer Science+Business Media, LLC. Used by permission.

Published online April 24, 2010.

\title{
Developing Water Stable Gliadin Films Without Using Crosslinking Agents
}

\author{
Narendra Reddy ${ }^{1}$ and Yiqi Yang ${ }^{1,2,3}$
}

1. Department of Textiles, Clothing, \& Design, 2. Department of Biological Systems Engineering, and 3. Nebraska Center for Materials and Nanoscience, University of Nebraska-Lincoln

Corresponding author - Yiqi Yang, 234 HECO Building, East Campus, University of Nebraska-Lincoln, Lincoln, NE 68583-0802, USA; email yyang2@unl.edu

\begin{abstract}
For the first time, gliadin films with excellent strength and water stability have been developed without using any crosslinking agents. So far, it has not been possible to obtain water stable gliadin films even after crosslinking. In this research, a novel method of using aqueous urea and ethanol has been developed to obtain highly water stable gliadin films without using crosslinking chemicals. The effects of concentrations of gliadin, urea and ethanol on the strength of the films and the stability of the films in water at high temperatures and various $\mathrm{pH}$ conditions has been studied. Gliadin films developed in this research have strength of about $30 \mathrm{MPa}$ similar to the strength of previously reported gliadin films crosslinked with aldehydes and cysteine. Gliadin films obtained in this research were stable in $\mathrm{pH} 7.2$ water at $50{ }^{\circ} \mathrm{C}$ for 20 days. The gliadin films did not dissolve in $70 \%$ ethanol which readily dissolves gliadin powder.
\end{abstract}

Keywords: Gliadin, Films, Proteins, Water stability, Crosslinking

\section{Introduction}

Plant proteins such as wheat gluten and gliadin, soyproteins and zein have been extensively studied to develop films due to their unique properties, easy degradability after use and large availability at low costs [1-5]. In addition to films, plant proteins have also been used to develop regenerated protein fibers for various applica- tions [6-9]. However, films and fibers made from plant proteins have relatively poor mechanical properties and stability in water compared to similar materials made from synthetic polymers. Therefore, attempts have been made to improve the properties of plant protein based films and fibers using chemical and physical modifications $[1,3,5,10-12]$.

Among plant proteins, wheat proteins are preferred for making films due to their selective barrier properties to gases, high elasticity and other favorable film forming properties [4, 11, 12]. Gliadins are the low molecular weight wheat proteins that dissolve in aqueous ethanol. Previously, films were cast from gliadin using aqueous ethanol as the solvent and glycerol as the plasticizing agent [3, 4, 13]. The gliadin films made using ethanol as a solvent had poor mechanical properties and disintegrated in water immediately. Gliadin films were therefore crosslinked using various crosslinking agents such as glutaraldehyde, formaldehyde, glyoxal and cysteine to improve the mechanical properties and water stability [3, 4, 13]. Formaldehyde crosslinked gliadin films had strength of $30 \mathrm{MPa}$ compared to $10 \mathrm{MPa}$ for the non-crosslinked films at 50\% relative humidity. However, the crosslinked films lost their integrity at $90 \%$ relative humidity [4]. Similarly, crosslinking with cysteine provided good strength and better water stability to gliadin films and the films had strength of about $4 \mathrm{MPa}$ at $90 \%$ relative humidity [7]. In another report, gliadin films crosslinked with formaldehyde, glu- 
taraldehyde and glyoxal had strength ranging from 2 to $7 \mathrm{MPa}$ and the films were stable in water at $23^{\circ} \mathrm{C}$ [13]. Although formaldehyde crosslinked gliadin films were stable in water, it is preferable not to use crosslinkers such as formaldehyde, especially for films used in food applications.

It has been previously reported that intramolecular disulfide bonds in gliadin proteins experience irreversible transformation into intermolecular bonds when dissolved in high concentration urea solutions [14]. This transformation increases the molecular weights of the gliadins. The higher molecular weight gliadin proteins will have better mechanical properties and water stability compared to similar materials made from low molecular weight gliadin proteins. We have recently developed high quality protein fibers from gliadin using aqueous urea and sodium sulfite [9]. The intermolecular transformation of disulfide bonds in gliadin proteins in high concentration urea solutions provided excellent mechanical properties and water stability to the gliadin fibers [9]. Attempts in our laboratory to develop gliadin films using the method used to produce the fibers were unsuccessful since the high concentrations of urea $(8 \mathrm{M})$ used precipitated upon drying and could not be removed without disrupting the films.

In this research, we have developed gliadin films using a novel approach of dissolving gliadin using both aqueous ethanol and urea solutions. The effect of concentrations of gliadin, ethanol and urea on the strength of the films and the stability of the films in water at various $\mathrm{pH}$ conditions and temperatures has been studied. The water vapor permeability and changes in the color, physical structure and thermal behavior of the films were also examined.

\section{Experimental}

\section{Materials}

Gliadin was extracted from commercially available wheat gluten (WHETPRO 80) obtained from Archer Daniels Midlands Company, Decatur, IL. Polylactic acid (PLA) pellets were supplied by Cargill, Minneapolis, MN. Ethanol, urea and sodium sulfite used for the study were reagent grade chemicals purchased from VWR International, Bristol, CT. Urea was used as the swelling agent and sodium sulfite was used as the reducing agent to assist the breaking of disulfide bonds and make the gliadin proteins soluble.

\section{Methods}

\section{Extracting Gliadin}

Wheat gluten was treated with $70 \%(\mathrm{v} / \mathrm{v})$ ethanol in 1:4 wheat gluten to ethanol ratio at room temperature for about $24 \mathrm{~h}$ under constant stirring. The wheat gluten mixture was then centrifuged at 9,000 rpm for $15 \mathrm{~min}$ and the supernatant was collected. Ethanol was evaporated from the supernatant to obtain the dissolved gliadin.

\section{Preparing Gliadin Films}

Gliadin films were cast using aqueous solutions of ethanol and urea. The film forming conditions such as the concentration of gliadin $(6-9 \%, \mathrm{w} / \mathrm{w})$, urea $(4-6 \mathrm{M})$ and ethanol $(30-90 \%, w / w)$ in water were varied to obtain films.

Films were cast on Teflon coated glass plates and $50 \mathrm{~g}$ of the film forming solution was used for each condition. The required amount of gliadin was first dissolved in urea solution of a known concentration with $1 \%(\mathrm{w} / \mathrm{w})$ sodium sulfite as the reducing agent. After dissolving the gliadin initially in the urea solution, ethanol equivalent to the amount of urea solution used was added and the mixture was allowed to age for $24 \mathrm{~h}$ at room temperature for the proteins to dissolve completely. The dissolved gliadin solution was poured onto Teflon coated glass plates and the ethanol was allowed to evaporate. It took about 3-6 h for most of the ethanol to evaporate under ambient conditions and for the proteins to form a stable film. The proteins in the films were precipitated using $10 \%(\mathrm{w} / \mathrm{w})$ sodium sulfate solution. After about $10 \mathrm{~min}$ of coagulation, the salt solution was drained and the films were then washed first in cold water and later in warm water $\left(45-50^{\circ} \mathrm{C}\right)$ several times to remove salt and urea. The washed films were dried under ambient conditions and later peeled from the glass plates. Thickness of the films was measured using a thickness gauge (AMES, Model: LG2600, Waltham, MA) with an accuracy of $1 \mu \mathrm{m}$. Average thickness of the films produced in this research was $100 \pm 8 \mu \mathrm{m}$ (one standard deviation).

The PLA pellets were ground into powder and dissolved $(7 \% \mathrm{w} / \mathrm{w})$ in chloroform. The solution was poured onto Teflon coated glass plates and the chloroform was evaporated to obtain the PLA films.

\section{Confirming Removal of Urea}

FTIR spectra of gliadin films and urea were collected to detect if any urea was present in the gliadin films after washing. Spectra of the film and urea powder were collected on a Thermo (Nicolet 380) total attenuated reflectance FTIR. Each sample was scanned 64 times at a frequency of $32 \mathrm{~cm}^{-1}$. Washing the gliadin films in water was effective in removing most of the urea from the films based on the FTIR spectrum in Figure 1. The typical absorption peaks of urea at about $1682 \mathrm{~cm}^{-1}(\mathrm{C}=\mathrm{O}$ stretching) and at 3320 and $3420 \mathrm{~cm}^{-1}$ (N-H stretching) are seen in the urea spectrum but are absent in the gli- 


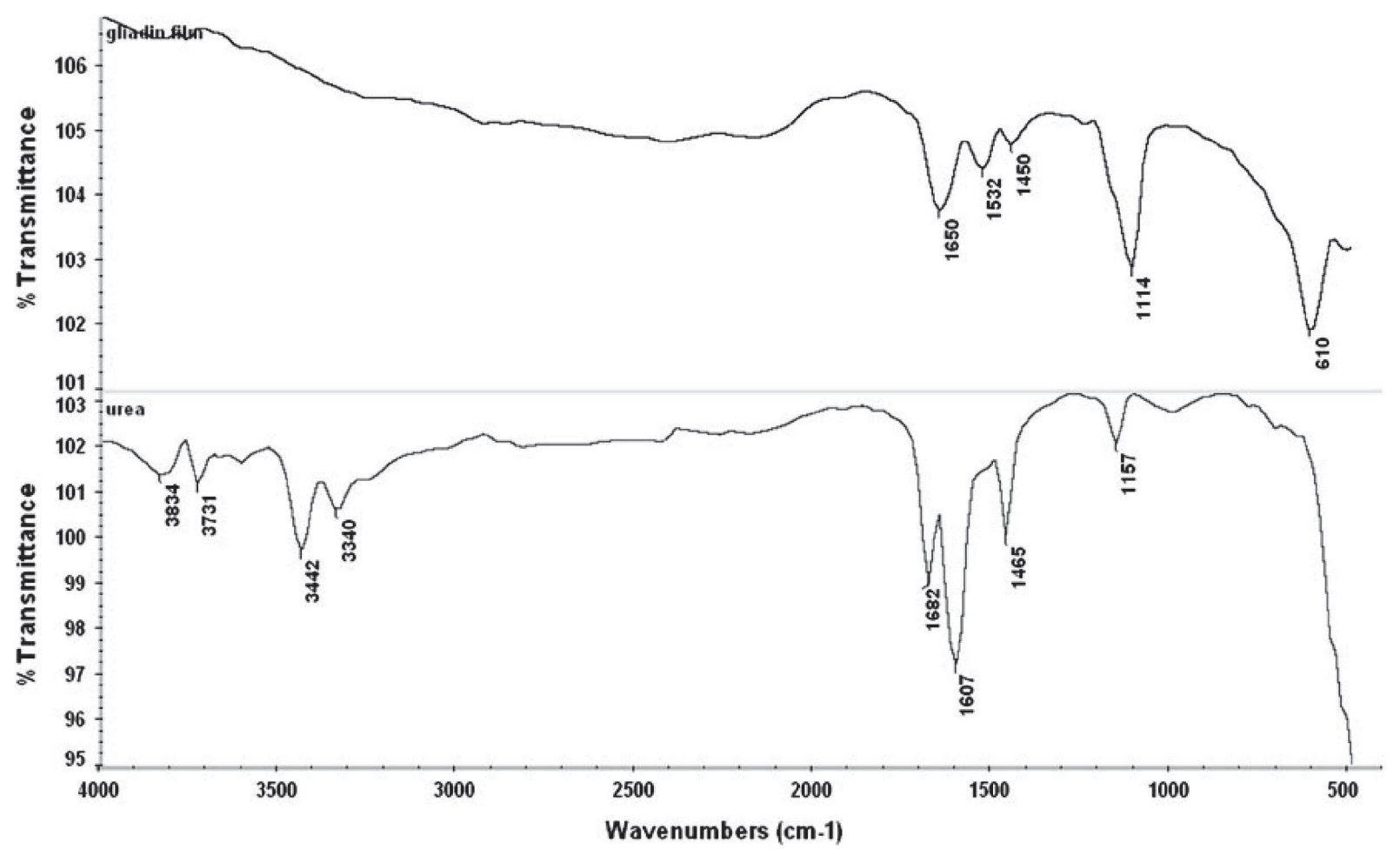

Figure 1. FTIR spectra shows that the gliadin films do not show any urea peaks indicating that most of the urea was removed from the films during washing.

adin films [15]. In addition, a spectrum of pure gliadin powder was subtracted from the gliadin film spectrum and the spectrum after subtraction did not show any match with urea confirming that the films did not contain detectable urea.

\section{Tensile Properties}

The tensile properties of the gliadin films were determined on an MTS tensile tester (MTS Corporation, Model: Qtest 10) according to ASTM standard D 88202. Testing was done on five samples each measuring $10 \times 1 \mathrm{~cm}$ randomly cut from the cast films. Three replications were done for a total of 15 tests for each condition. Before testing, all samples were conditioned for at least $40 \mathrm{~h}$ in a conditioning chamber maintained at $23 \pm 0.5^{\circ} \mathrm{C}$ and $50 \pm 1 \%$ relative humidity.

\section{Physical Structure}

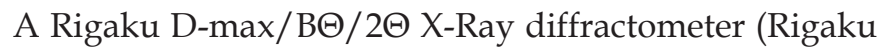
Americas, Woodlands, TX) with Bragg - Brentano parafocusing geometry, a diffracted beam monochromator, and a copper target X-ray tube set to $40 \mathrm{kV}$ and $30 \mathrm{~mA}$ was used to observe the diffraction pattern of the gliadin powder and films. The diffraction patterns were recorded for $2 \theta$ values ranging from $5^{\circ}$ to $40^{\circ}$ on film samples measuring $2 \times 2 \mathrm{~cm}$. Gliadin powder was made into a pellet of about $5 \mathrm{~mm}$ thick in a hydraulic press operated at 20,000 PSI for the X-ray analysis.

\section{Water Vapor Permeability}

The water vapor permeability of the gliadin films was determined according to ASTM standard E96/E96M-05. Three replications were done and the average water vapor permeability is reported along with \pm one standard deviation.

\section{Color of Films}

The color of the gliadin films was measured on a spectrophotometer (Hunterlab Model: Ultrascan XE) using a 1 inch viewing port, D65 illuminant and $10^{\circ}$ observer. Samples were conditioned for at least $48 \mathrm{~h}$ before conducting the test. Two layers from the same gliadin films were tested at three different places to obtain the yellowness and the $L^{*}, a^{*}$ and $b^{*}$ values. The test was repeated on three different films and the average with \pm one standard deviations is reported.

\section{Resistance to Hydrolysis at Various $p H$ Conditions}

Gliadin and PLA films were treated in phosphate buffered saline water ( $\mathrm{pH} \mathrm{7.2)}$ at $50{ }^{\circ} \mathrm{C}$ for up to 20 days. In addition, the films were also treated in water adjusted to 


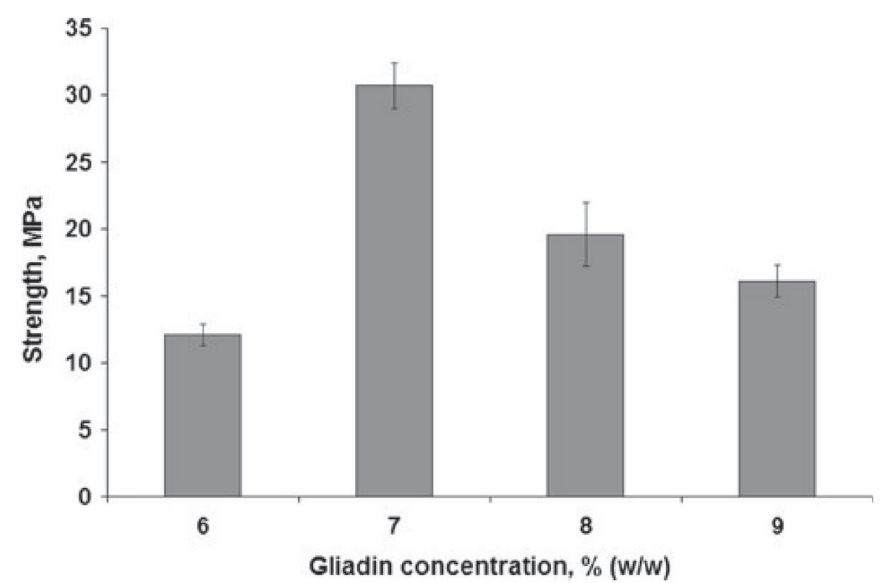

Figure 2. Effect of gliadin concentration on the strength of the gliadin films. Films were cast using equal amounts of $4 \mathrm{M}$ urea solution and $90 \%$ ethanol and $1 \%$ sodium sulfite.

various $\mathrm{pH}$ conditions $\left(3,5,7,9\right.$ and 11) for $1 \mathrm{~h}$ at $90{ }^{\circ} \mathrm{C}$. About $0.2 \mathrm{~g}$ of the films were put in water and taken out after a specified time. The samples taken out were rinsed in distilled water and allowed to dry in a standard conditioning chamber maintained at $23 \pm 0.5^{\circ} \mathrm{C}$ and $50 \pm 1 \%$ relative humidity. The weight of the conditioned specimen after treating in water was determined and the $\%$ weight loss of the films in water was calculated according to Equation 1:

$$
\% \text { Weight loss }=\frac{\mathrm{W}_{1}-\mathrm{W}_{2}}{\mathrm{~W}_{1}} \times 100
$$

where $W_{1}=$ Weight of film before treatment

$\mathrm{W}_{2}=$ Weight of film after treatment

\section{Thermal Analysis}

A differential scanning calorimeter (Mettler) was used to observe the thermal behavior of the gliadin films. Films were scanned from 25 to $240{ }^{\circ} \mathrm{C}$ at a scanning rate of $5{ }^{\circ} \mathrm{C} / \mathrm{min}$. The heating cycle was repeated twice on the same sample and the second scans were collected to observe the glass transition temperature $(\mathrm{Tg})$.

\section{Results and Discussion}

\section{Effect of Gliadin Concentration}

Films with good tensile strength were obtained with a gliadin concentration of $7 \%$ as seen from Figure 2 . Below $6 \%$, there were not enough proteins and the films disintegrated upon washing in water to remove the urea. Above $9 \%$, the proteins did not completely dissolve in

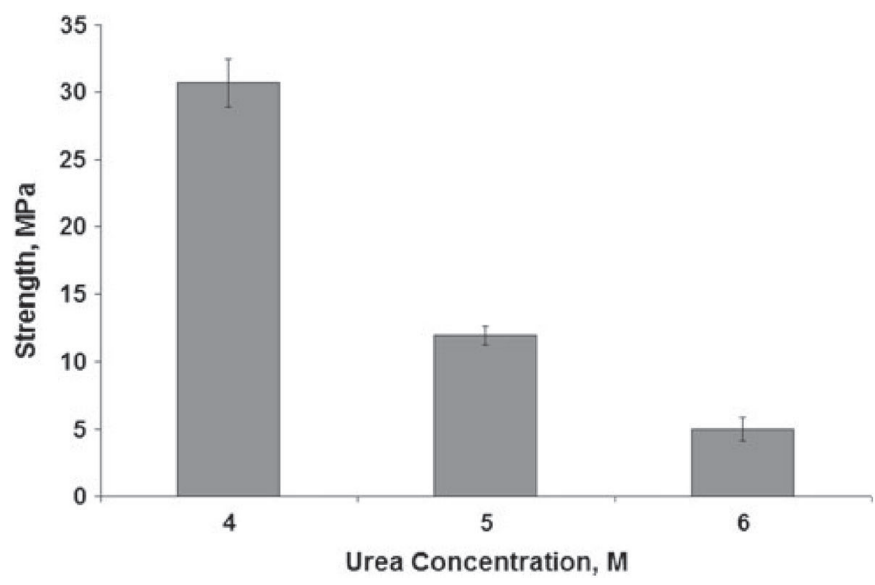

Figure 3. Effect of urea concentration on the strength of the gliadin films. Films were cast using $7 \%$ gliadin and equal amounts of urea solution and $90 \%$ ethanol and 1\% sodium sulfite.

the mixed solvent system. The strength of the $7 \%$ gliadin films $(30 \mathrm{MPa})$ is similar to the highest strength previously reported for crosslinked gliadin films under similar relative humidity. Previously, formaldehyde and cysteine crosslinked gliadin films have been reported to have strength of about $30 \mathrm{MPa}$ compared to the strength of $10 \mathrm{MPa}$ for the non-crosslinked films [4, 13]. It should be noted that the strength of the gliadin films developed in this research may also be increased further by crosslinking.

\section{Effect of Urea Concentration}

The concentration of urea used had considerable effect on the strength of the gliadin films as seen from Figure 3. A urea concentration below $4 \mathrm{M}$ did not completely dissolve the proteins and at concentrations above $6 \mathrm{M}$ there was too much urea in the cast films and the urea precipitated upon drying. Gliadin films had the highest strength of $30 \mathrm{MPa}$ when dissolved using $4 \mathrm{M}$ urea. Above $4 \mathrm{M}$ urea, it was not possible to wash the excess urea and obtain continuous films. Previously, gliadin films were cast using ethanol as a solvent and to the best of our knowledge, no reports are available on using urea solutions as a solvent to make films from gliadin. However, urea solutions are routinely used to dissolve proteins and make fibers $[7,8]$. In the case of gliadin, it has been reported that high concentrations of urea can irreversibly transform the intramolecular disulfide bonds into intermolecular disulfide bonds. Such transformations of the disulfide bonds lead to intermolecular crosslinking and therefore increase in the molecular weight of the proteins that provides better strength and stability to the films [14]. 


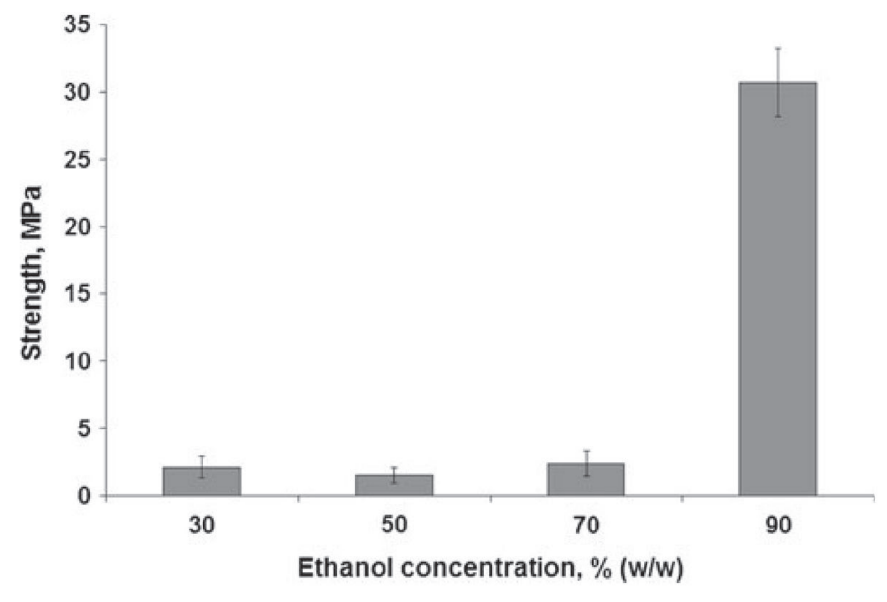

Figure 4. Effect of ethanol concentration on the strength of the gliadin films. Films were cast using $7 \%$ gliadin and equal amounts of $4 \mathrm{M}$ urea solution and ethanol and $1 \%$ sodium sulfite.

\section{Effect of Ethanol Concentration}

Among the range of ethanol concentrations studied, only a mixture of $90 \%$ ethanol and $4 \mathrm{M}$ urea solutions gives the films good strength as seen from Figure 4 . This should be due to the effective concentration of ethanol in the solvent mixture. As mentioned in the experimental section, the ethanol and urea solutions are mixed in equal proportions to dissolve the proteins. However, the urea solution $(4 \mathrm{M})$ contains considerable amounts of water that will reduce the overall concentration of ethanol when it is mixed with urea solution. When $90 \%$ ethanol is mixed with equal amounts of $4 \mathrm{M}$ urea solution to dissolve gliadin, the effective concentration of ethanol in the total solution will be about $70 \%$. Gliadin dissolves easily in $70 \%$ ethanol and therefore, the films will have good tensile strength when cast using equal amounts of $90 \%$ alcohol and $4 \mathrm{M}$ urea solution.

\section{Physical Structure}

Both the gliadin film and gliadin powder have similar diffracting peaks indicating that the gliadin dissolution method used to make the films and the intermolecular transformation did not alter the physical structure of the gliadin proteins. The most prominent gliadin peak is seen at about $18^{\circ}$ and there is another small peak at about $8^{\circ}$ as seen from Figure 5. Although the physical structure of gluten proteins has not been studied extensively, it has been shown that gluten and gliadin have similar crystal structure with two prominent peaks producing d-spacings of 62 and $48 \AA$ [16, 17]. Further analysis of the physical structure was not possible due to the weak and diffuse diffraction obtained from the films.

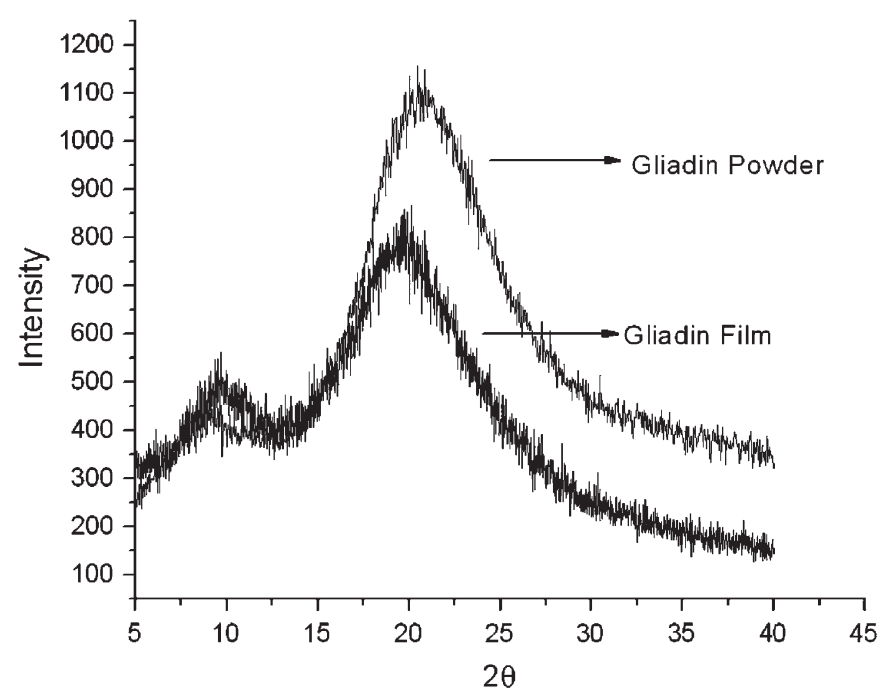

Figure 5. X-ray diffraction pattern of gliadin films compared to gliadin powder.

\section{Water Vapor Permeability}

Gliadin films made using 7\% gliadin, $4 \mathrm{M}$ urea and $90 \%$ ethanol had a water vapor permeability of $26.6 \pm 2.9 \mathrm{~g} \mathrm{~h}^{-1} \mathrm{~m}^{-2}$, similar to those previously reported for crosslinked and non-crosslinked gliadin films [3, 4, $12,13]$.

\section{Color}

Gliadin films made using the optimum conditions (7\% gliadin, $4 \mathrm{M}$ urea and $90 \%$ ethanol) had CIE yellowness index of $14 \pm 3$. The yellowness of gliadin films previously developed has not been reported but non-crosslinked and gliadin films crosslinked with formaldehyde, glutaraldehyde and glyoxal were reported to have $L^{*}$ values ranging from 95.6 to $97.8, a^{*}$ values of -0.21 to +1.06 and $b^{*}$ values of 3.4-11.8. Films developed in this research, had corresponding $\mathrm{L}^{*}, \mathrm{a}^{*}$ and $\mathrm{b}^{*}$ values of $90 \pm 0.3,-2.7 \pm 0.4$ and $8.5 \pm 2.0$, respectively. The higher thickness and use of chemicals such as urea and sodium sulfite are some of the reasons for the varying color coordinates of the films developed in this research compared to those reported in literature.

\section{Resistance to Hydrolysis}

Gliadin films are stable and lose only about $12-50 \%$ of their weight even after being treated in $90{ }^{\circ} \mathrm{C}$ water for $1 \mathrm{~h}$ at various $\mathrm{pH}$ 's as seen from Figure 6 . The films have higher weight loss in $\mathrm{pH} 11$ water since proteins readily hydrolyze in alkaline conditions. The PLA films have slightly lower weight loss at $\mathrm{pH} 3$ compared to the other $\mathrm{pH}$ 's studied. The PLA films have highest weight loss 


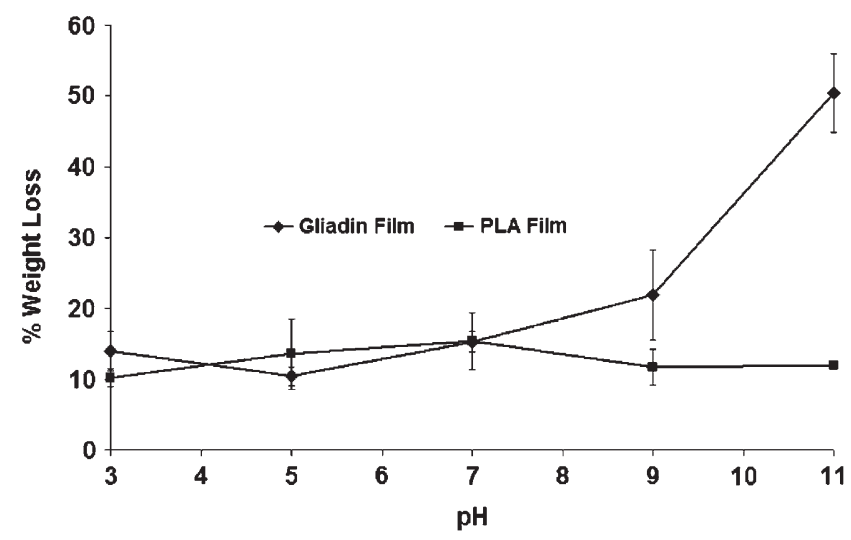

Figure 6. Weight losses of the gliadin and PLA films treated in $90{ }^{\circ} \mathrm{C}$ water for $1 \mathrm{~h}$ at various $\mathrm{pH}$ conditions. The gliadin films were cast using $7 \%$ gliadin, equal amounts of $4 \mathrm{M}$ urea solution and $90 \%$ ethanol with $1 \%$ sodium sulfite.

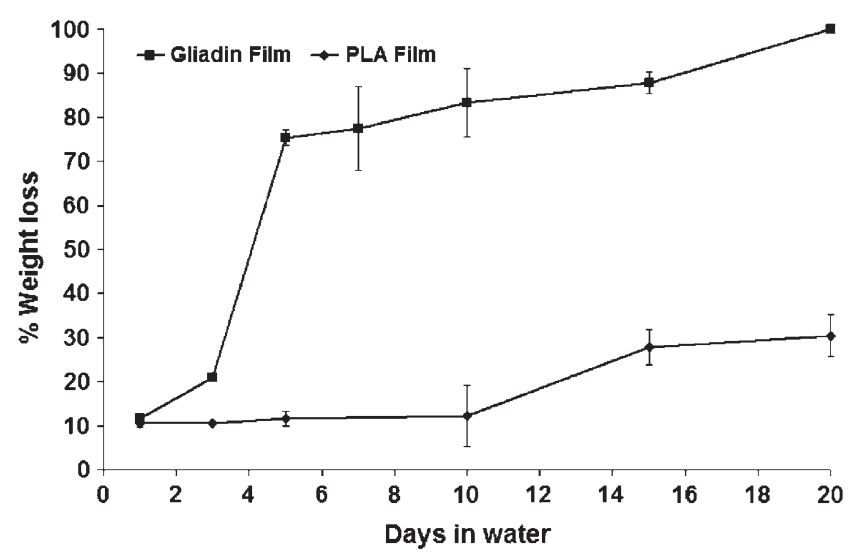

Figure 7. Weight loss of the gliadin and PLA films after being treated in $\mathrm{pH} 7.2,50{ }^{\circ} \mathrm{C}$ water from 1 to 20 days. The gliadin films were cast using $7 \%$ gliadin, equal amounts of $4 \mathrm{M}$ urea solution and $90 \%$ ethanol with $1 \%$ sodium sulfite. when treated in $\mathrm{pH} 7$ water and similar weight loss of about $12 \%$ at $\mathrm{pH} 9$ and 11 . So far, it has not been possible to obtain gliadin films with good water stability even after crosslinking. Gliadin films previously crosslinked with formaldehyde were not stable under $90 \%$ relative humidity and those crosslinked with glutaraldehyde had about $30 \%$ weight loss after being treated in $23^{\circ} \mathrm{C}$ water for $24 \mathrm{~h}[3,4,13]$.

Gliadin films developed in this research were also stable in $\mathrm{pH} 7.2$ water for up to 20 days but lost weight continuously as seen in Figure 7. The highest loss in weight was between 3 and 5 days and there was a gradual weight loss from 5 to 20 days. The gliadin films had disintegrated completely after 20 days in $\mathrm{pH} 7.2,50{ }^{\circ} \mathrm{C}$ water. The PLA films have much better stability than the gliadin films as seen from Figure 6. PLA films lose about $10 \%$ of their weight after 5 days and have a maximum weight loss of $30 \%$ after 20 days in $\mathrm{pH} 7.2$ water at $50{ }^{\circ} \mathrm{C}$. The formation of intermolecular disulfide bonds and increase in the molecular weight of the proteins should be the major reason for the high water stability of gliadin films developed in this research compared to the stability of crosslinked gliadin films previously developed [14].

\section{Thermal Analysis}

The DSC thermogram of the gliadin films in Figure 8 shows a Tg peak at about $164{ }^{\circ} \mathrm{C}$. It has been reported that native gliadins have $\mathrm{Tg}$ around $150{ }^{\circ} \mathrm{C}$ and that crosslinking increases the $\mathrm{Tg}$ of gliadin due to the decreases in the mobility of the polymers [13]. Gliadin films crosslinked with glutaraldehyde and glyoxal showed increase in $\mathrm{Tg}$ to 159 and $156^{\circ} \mathrm{C}$ compared to $153^{\circ} \mathrm{C}$ for the non-crosslinked films whereas films cross-
Figure 8. DSC thermogram of gliadin films. The films were made with $7 \%$ gliadin, $4 \mathrm{M}$ urea solution and $90 \%$ aqueous ethanol were scanned at a rate of $5^{\circ} \mathrm{C} / \mathrm{min}$ and the second scans were collected for analysis to reveal the $\mathrm{Tg}$.

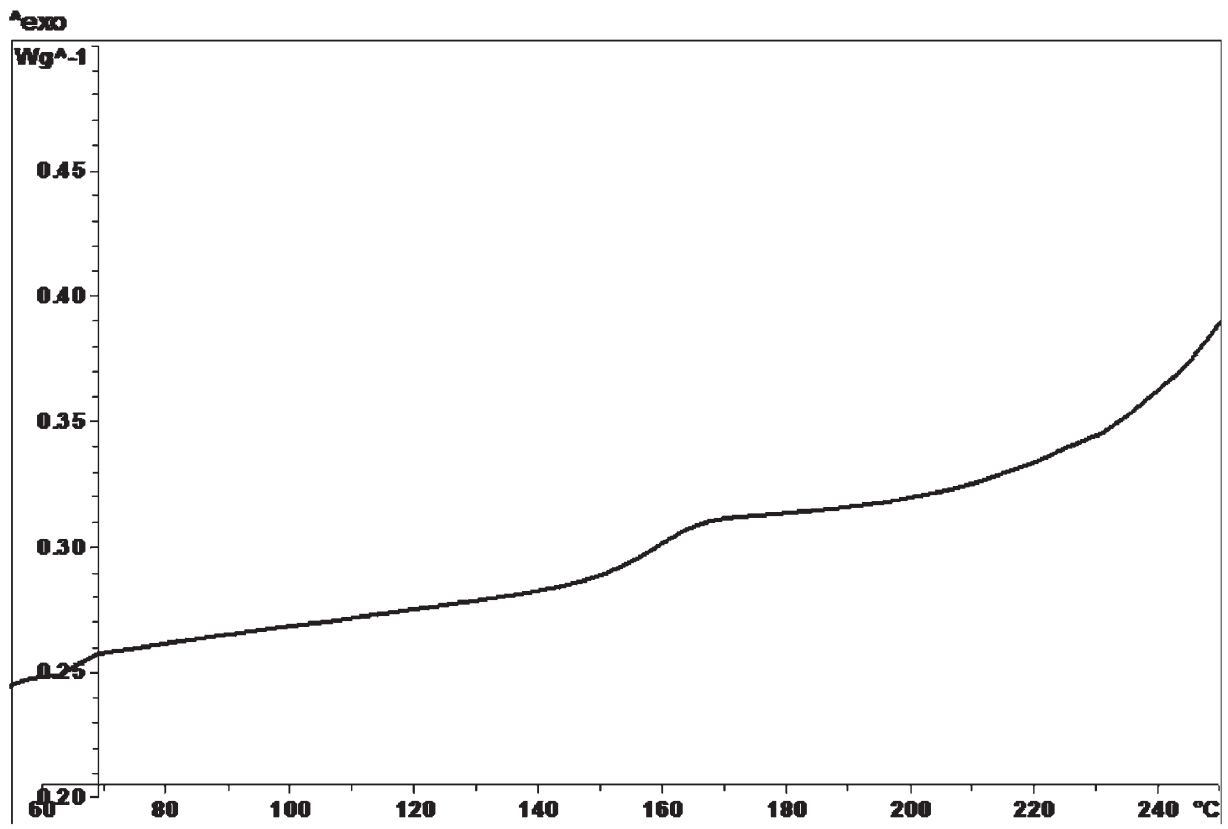


linked with formaldehyde had much higher increase in $\mathrm{Tg}$ to about $177{ }^{\circ} \mathrm{C}$ [13]. The higher Tg of gliadin films developed in this research compared to native gliadins indicates that the extent of crosslinking obtained in this research is between that of the formaldehyde and glutaraldehyde or glyoxal crosslinked films. The DSC curve does not show any urea melting peaks between 130 and $135{ }^{\circ} \mathrm{C}$ also suggesting that there was no urea in the films.

\section{Conclusions}

Gliadin films with excellent strength and water stability have been developed without using any crosslinking agents. The molecular transformation of disulfide bonds in gliadin proteins in high concentration urea solutions increases the molecular weight, crosslinks the proteins and provides high strength and water stability to the films. FTIR spectra and DSC curves show that urea was removed from the films during washing. Films developed in this research have strength similar to that of crosslinked gliadin films previously developed but with much better water stability. However, the films have low elongation (2-5\%) since plasticizers were not used. The films have good water vapor permeability with slight yellow color. Thermal analysis indicates an increase in the Tg of gliadin proteins but the physical structure of the proteins remains unchanged. Further research is necessary to understand the effects of plasticizers and crosslinking with crosslinking agents such as aldehydes on the mechanical properties and water stability of the gliadin films developed using the mixed solvent system.

Acknowledgments - This research was partially supported with funds from Nebraska Wheat Board, The Consortium for Plant Biotechnology Research, Inc by DOE prime agreement No. DE-FG36-02G012026, Archer Daniel Midland Company, USDA Hatch Act, the Agricultural Research Division at the University of Nebraska-Lincoln, and by Multi State Research Project S-1026. The financial sponsors do not endorse the views expressed in this publication.

\section{References}

1. Gennadios A, Rhim JW, Handa A, Weller CL, Hanna MA (1998) J Food Sci 63(2):1

2. Roy S, Weller CL, Gennadios A, Zeece MG, Testin RF (199) J Food Sci 64(1):57

3. Munoz PH, Kanavouras A, Villalobos R, Chiralt AJ (2004) J Agric Food Chem 52:7897

4. Munoz PH, Rubio A, Lagaron JM, Gavara R (2004) Biomacromolecules 5:415

5. Munoz PH, Villalobos R, Chiralt A (2004) Food Hydrocoll 18:403

6. Yang Y, Wang L, Li S (1996) J Appl Polym Sci 59(3):433

7. Zhang X, Min BG, Kumar S (2003) J Appl Polym Sci 90(3):716

8. Reddy N, Yang Y (2007) Biomacromolecules 8:638

9. Reddy N, Yang Y (2008) J Mater Sci Mater Med 19:2055

10. Huang HC, Hammond EG, Reitmeier CA, Myers DJ (1995) J Am Oil Chem Soc 72(12):1453

11. Lens JP, Mulder WJ, Kolster P (1999) Cereal Food World 44(1):5

12. Park SK, Bae DH, Rhee KC (2000) J Am Oil Chem Soc 77(8):879

13. Munoz P, Kanavouras A, Lagaron JM, Gavara R (2005) J Agric Food Chem 53:8216

14. Beckwith AC, Wall JS, Jordan RW (1965) Arch Biochem Biophys 112:16

15. Larrubial MA, Ramis G, Busca G (2000) Appl Catal B 27:145

16. Grosskreutz JC (1960) Biochim Biophys Acta 38:400

17. Traub W, Hutchinson JB, Daniels DGH (1957) Nature 179:769 